\title{
Use of thermally treated waste biological sludge as dye absorbent
}

\author{
G. Annadurai ${ }^{a}$, R.S. Juang ${ }^{\mathrm{b}}$, P.S. Yen ${ }^{\mathrm{a}}$, D.J. Lee ${ }^{\mathrm{a}, *}$ \\ ${ }^{a}$ Chemical Engineering Department, National Taiwan University, Taipei 106, Taiwan, ROC \\ ${ }^{\mathrm{b}}$ Chemical Engineering Department, Yuan Ze University, Chung-Li 320, Taiwan, ROC
}

\begin{abstract}
The capacity of adsorbent recycled from microwave thermal treatment to remove a synthetic dye, Rhodamine $6 \mathrm{G}$, from a water bath, was examined. The acidified, dewatered sludge was microwave heated for 1-4 min. Batch adsorption tests were conducted on this sludge at various $\mathrm{pH}$ values and solution temperatures. Equilibrium of dye adsorption was obtained in $30 \mathrm{~h}$. Three kinetic models-pseudo first-order, pseudo second-order and intra-particle diffusion - were applied to elucidate the adsorption kinetic data. Experimental results indicate that higher adsorption efficiency could be derived at higher $\mathrm{pH} /$ temperature levels. Moreover, the sample treated for $1 \mathrm{~min}$ by microwaves adsorbed more dye than did the sample so treated for $4 \mathrm{~min}$. Sludge samples were also characterized to interpret the experimental findings. Energy cost analysis demonstrated the feasibility of the present microwave process.
\end{abstract}

(c) 2002 Elsevier Science Ltd. All rights reserved.

Keywords: Dye removal; Absorbent; Microwave treatment; Kinetics

\section{Introduction}

Textile and tannery effluents are some of the most polluting industrial wastes. Their treatment and disposal involves significant practical difficulty. Conventional primary and secondary systems of wastewater treatment plants are not suited to treating these effluents as the dyes are typically non-biodegradable (Mckay et al., 1981, 1982; Gurusamy and Elangovan, 1992; Annadurai et al., 1999). Physical and chemical processes of color removal have been investigated (Diez et al., 1999; Singh et al., 1984; Sunil et al., 1987; Panswed and Wangchaisuwan, 1986; Yoshida et al., 1993; Nassar and Guendi, 1991; Nawar and Doma, 1989), including coagulation, flocculation, biosorption, photo-decomposition and ultrafiltration (Asfour et al., 1985; Gupta et al., 1989). However, pulp and paper or textile tannery industries have seldom applied the aforementioned processes in treating their wastewater due to the relatively high operational costs and the low removal ratios (Lee et al., 1990; Mall and Upaphyay, 1995).

*Corresponding author. Tel.: + 886-2-363-5230; fax: + 8862-362-3040.

E-mail address: djlee@ccms.ntu.edu.tw (D.J. Lee).
Waste biological sludge is formed in vast quantities in wastewater treatment by the conventional activated sludge process. Sludge treatment/disposal represents $50 \%$ of the capital and operational costs of a wastewater treatment plant (Vriens et al., 1989; Isaacs et al., 1995; Jeyaseelan and Qing, 1994; Aksu and Yener, 1998). Activated sludge is a biomass containing mainly bacteria and protozoa. The cell walls of the bacteria mainly consist of various organic compounds including chitin, acidic polysaccharides, lipids, amino acids and other cellular compounds that can adsorb both heavy metal ions and various organics (Brandt et al., 1997). The activated sludge can thus adsorb these compounds (Zumriye et al., 1999; Bux et al., 1999; Ulku et al., 1999). Reusing waste activated sludge is appealing in terms of resource utilization. However, the use of original sludge suffers the disadvantages of continuous change in quality and of odor emission during storage. Martin et al. (1999) postulated that microwave-treated sludge could be used utilized as a dye adsorbent. The authors noted that their treated sludge sample could compete with commercial activated carbon adsorbent in terms of dye removal efficiency. Dry powdered adsorbent usually provides much greater adsorption and is more stable in storage than related liquid products. 
This work adopts a procedure similar to that described by Martin et al. (1999), for preparing the microwave treated sludge samples. Batch adsorption tests were conducted on a commercial dye, Rhodamine 6G, in solutions with different $\mathrm{pH}$ values and at different temperatures. Adsorption capacities of sludge treated at various times were compared. An energy cost estimate demonstrates the feasibility of applying this process to dye removal.

\section{Experimental}

The sewage sludge samples were taken from the reflux stream of recycled activated sludge from the MinShen Sewage Treatment Plant, Taipei, which handles $15500 \mathrm{~m}^{3} /$ day of wastewater and uses primary, secondary, and tertiary treatments. The raw sewage is screened, degritted, and settled in the primary clarifiers. Then, the treated sewage goes to the secondary treatment stage, which involves the conventional activated sludge process. Part of the waste activated sludge from the secondary clarifier is recycled back into the aerated tanks. Finally, the treated sludge passes a tertiary treatment process, which is comprised of filtration and disinfection stages. Three activated sludge samples were obtained from the recycled stream in the secondary treatment stage on various days. The sludge sediment was used as testing samples, whose solid weight fraction was measured at $0.27 \% \mathrm{w} / \mathrm{w}$. The zeta potential was measured via the zeta meter (Zeter-Meter System 3.0, Zeter-Meter Inc, USA). The result was $-19 \mathrm{mV}$. Particle size distribution (PSD) was measured via particle size analyzer (Coulter LS 230), giving an estimate for floc size of $95 \mu \mathrm{m}$.

The sludge was thermally treated according to the procedures of Martin, et al. (1999). The sludge was centrifugally dewatered to a solid content of approximately $10 \% \mathrm{w} / \mathrm{w}$. Then, it was mixed with acetic acid (1:1 by weight), according to the total sludge weight. Two 5-g samples of the acid/sludge mixture were heated up in a microwave oven at $800 \mathrm{~W}$, one for $1 \mathrm{~min}$ and the other for $4 \mathrm{~min}$. They were referred to as 1 -min and 4-min samples, respectively. Nitrogen gas was purged continuously through the oven to prevent any fire hazard. The treated sludge was black and is fragile. The BET specific surface area of the 1-min sample was 2.62 $\mathrm{m}^{2} / \mathrm{g}$, determined using a sorptiometer (Quanta Chrome Corporation NOVA, 2000). The thermally treated sludge sample was crushed and screened. Steam activation could markedly increase the surface area of the sample, but also increase the preparation costs as well.

The synthetic wastewater was made by mixing the dyes Rhodamine 6G (C.I. 45160, basic, red, molecular weight of 479) obtained from Sigma Co., with deionized water. The initial dye concentration was maintained at $20 \mathrm{mg} / \mathrm{l}$. Batch adsorption tests were undertaken on 1 $\mathrm{g}$ of treated sludge at solution $\mathrm{pH}$ from 4 to 8 and temperatures from 30 to $60{ }^{\circ} \mathrm{C}$. The adsorbent was placed in contact with $100 \mathrm{ml}$ of aqueous dye-solution in a $250-\mathrm{ml}$ flask agitated in a shaker bath (Firsiek model B603, Taiwan) at 180 r.p.m. for 2 days, during which period the solution was sampled every $4 \mathrm{~h}$. The solution containing the dye was centrifuged at 10000 r.p.m., and the dye concentration was analyzed using Hitachi UV/Visible Spectrophotometer (Model U-2000) at a suitable wavelength. Each experiment was duplicated under identical conditions to confirm the data's reproducibility.

Thermally treated activated sludge (1-min) that had adsorbed dye was fixed overnight with $2.0 \%(\mathrm{w} / \mathrm{v})$ glutaraldehyde. The sample was dehydrated by sequential immersion for $30 \mathrm{~min}$ by acetone at increasing concentrations $(20,30,60,80,90 \% \mathrm{w} / \mathrm{v}$ and twice anhydrous acetone). The dehydrated thermal activated sludge was dried and covered with a thin layer of gold. The surface of the thermal activated sludge was observed by scanning electron microscopy (JEOL Japan, model JSM-5600), operated at $15 \mathrm{kV}$.

\section{Results and discussion}

\subsection{Batch adsorption test}

Fig. 1 summarizes the adsorption kinetic data ( $q_{t}$ vs. $t$ ) at $\mathrm{pH} 7$ and $30{ }^{\circ} \mathrm{C}$. The dye adsorption of the 1 -min sample is faster than that of the 4-min sample. Moreover, the maximum amount of adsorbed dye $\left(q_{e}\right)$ is also higher for the former sample $(16.2 \mathrm{mg} / \mathrm{g})$ than for the latter $(13.2 \mathrm{mg} / \mathrm{g})$. The following three kinetic models are considered to interpret the experimental data. (1) Pseudo first-order equation (Ho and Mckay, 1998, 1999; Wu et al., 2001),

$\log \left(q_{e}-q_{t}\right)=\log q_{e}-\frac{k_{1}}{2.303} t$

where $k_{1}$ is the first-order rate constant; Eq. (2) is a pseudo second-order equation (Ho and Mckay, 1998, 2000),

$\frac{t}{q_{t}}=\frac{1}{k_{2} q_{e}^{2}}+\frac{t}{q_{e}}$

where $k_{2}$ is the second-order rate constant, and Eq. (3) is the intra-particle diffusion model (Weber and Morriss, 1963)

$q_{e}=k_{p} t^{1 / 2}$

where $k_{p}$ is the intra-particle diffusion rate constant. All 


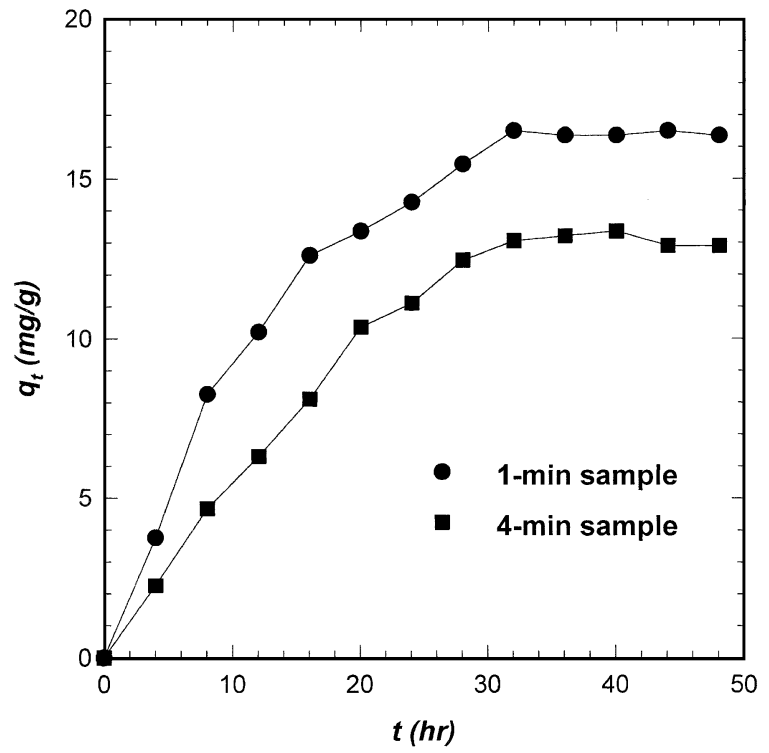

Fig. 1. Adsorption curves. $\mathrm{pH} 7.0,30{ }^{\circ} \mathrm{C}$.

three models can properly describe the adsorption kinetics. Figs. 2-4 reveal the fitting with Eqs. (1)-(3). Notably, each model can describe only a part of the kinetics. The first-order model best describes the data from 0 to $24 \mathrm{~h}$ of adsorption. The second-order model fits the data from 8 to $36 \mathrm{~h}$. The initial lag in Fig. 4 means that the intra-particle diffusion model fits best from 4 to $32 \mathrm{~h}$ of testing. Whether the surface reaction (single or two-step mechanisms for first-order or sec-

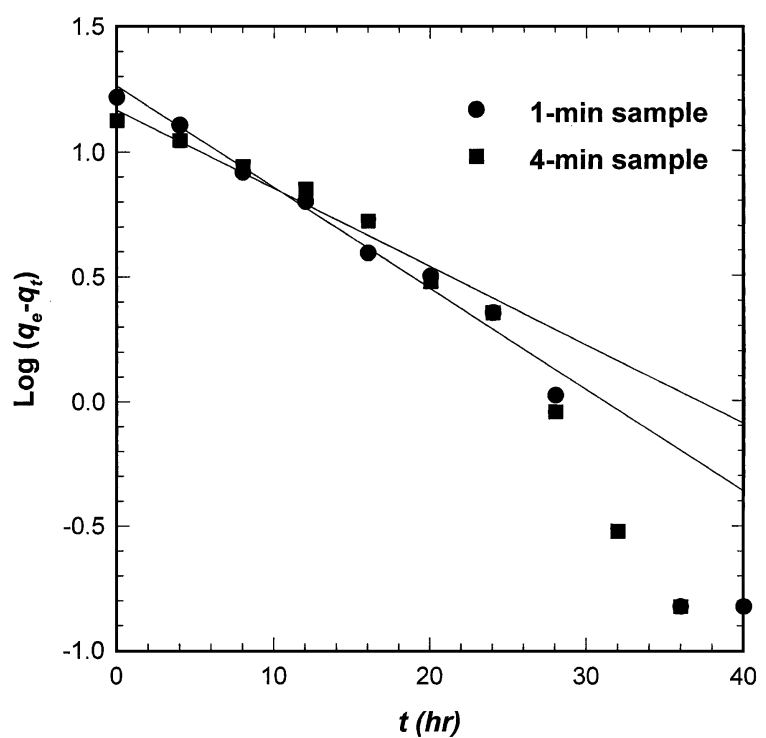

Fig. 2. Model fitting with Eq. (1).

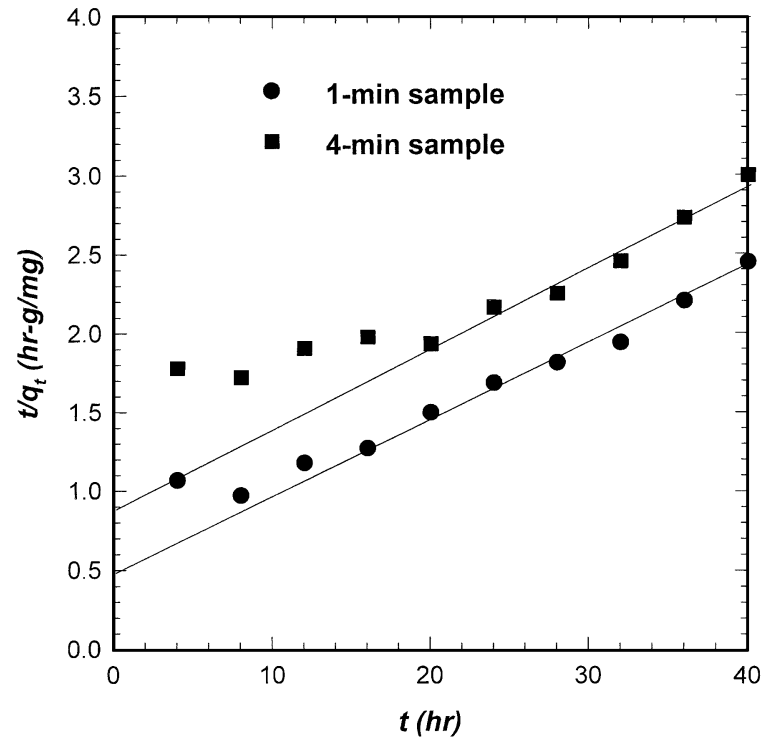

Fig. 3. Model fitting with Eq. (2).

ond-order kinetics) or the intra-particle diffusion controls the process can not yet be determined. Linear regression with Eqs. (1)-(3) was used to estimate the kinetic parameters according to the data's linear characteristics, described in Table 1. As expected, the rate constants for the 1-min sample exceed those for the 4min sample, corresponding to the observations of Fig. 1.

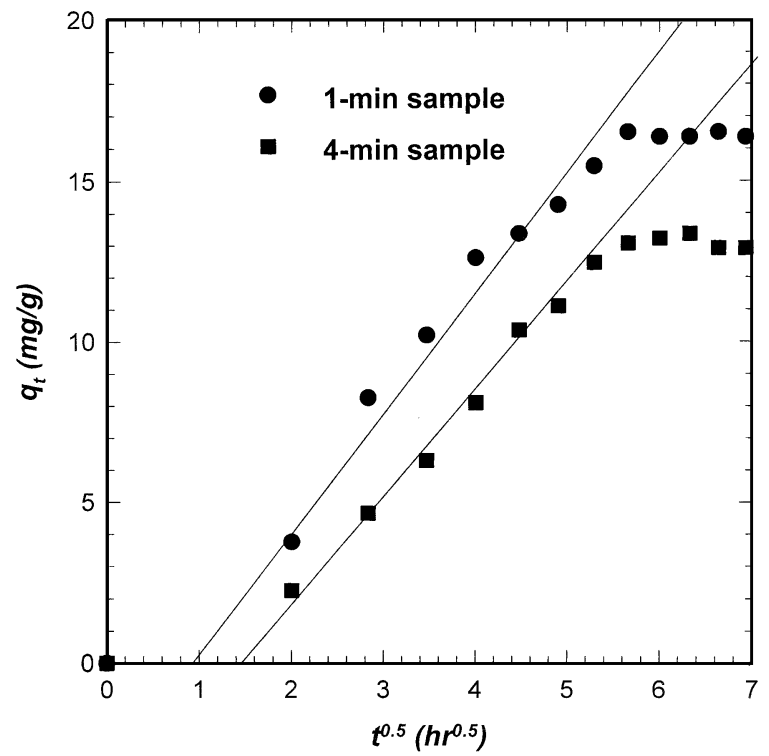

Fig. 4. Model fitting with Eq. (3). 
Table 1

Kinetic parameters determined using kinetic models, using data sampled at 4-36 h

\begin{tabular}{llllllr}
\hline Sample & $\begin{array}{l}k_{1} \\
(1 / \mathrm{h})\end{array}$ & $R^{2}$ & $\begin{array}{l}k_{2} \\
(\mathrm{~g} / \mathrm{mg} \cdot \mathrm{h})\end{array}$ & $R^{2}$ & $\begin{array}{l}k_{p} \\
\left(\mathrm{mg} / \mathrm{g} \cdot \mathrm{h}^{0.5}\right)\end{array}$ \\
\hline 1-min & 0.0933 & 0.981 & $1.65 \times 10^{-3}$ & 0.955 & 2.93 \\
4-min & 0.0755 & 0.969 & $3.66 \times 10^{-4}$ & 0.905 & 2.12 \\
\hline
\end{tabular}

\subsection{Equilibrium adsorption}

Fig. 5 shows the removal fractions of dye at $30{ }^{\circ} \mathrm{C}$, taking the $\mathrm{pH}$ value as a parameter. The removal ratio increases with $\mathrm{pH}$ value. The removal ratio of the 1min sample reached $80.5 \%(\mathrm{pH} 7.0)$ with a $\mathrm{pH}$ above 5.0. However, the dye adsorption of the 4-min sample was only $63.5 \%(\mathrm{pH} \mathrm{7.0)}$, less than that of the 1-min sludge. Restated, over-cooking the sludge yields a less efficient dye adsorbent. Such an observation is attributable to the surface areas being lower in the 4-min than in the 1-min sample (shown later).

Fig. 6 presents the zeta potential against the $\mathrm{pH}$ value for 1-min sludge powders before and after dye adsorption. The original powder possessed a negative surface charge of $-32 \mathrm{mV}$ at $\mathrm{pH} 6.8$. As $\mathrm{pH}$ falls, the zeta potential becomes less negative, and is neutralized at an approximate $\mathrm{pH}$ of 4.3. Following adsorption, the zeta potential continues to rise as $\mathrm{pH}$ falls. However, the corresponding zeta potential at a given $\mathrm{pH}$ is less negative than that of the original powder. In the acidic environment, the hydrogen ions compete with the dye molecules to occupy the adsorption sites. Both factors negatively affect dye adsorption since dye molecules

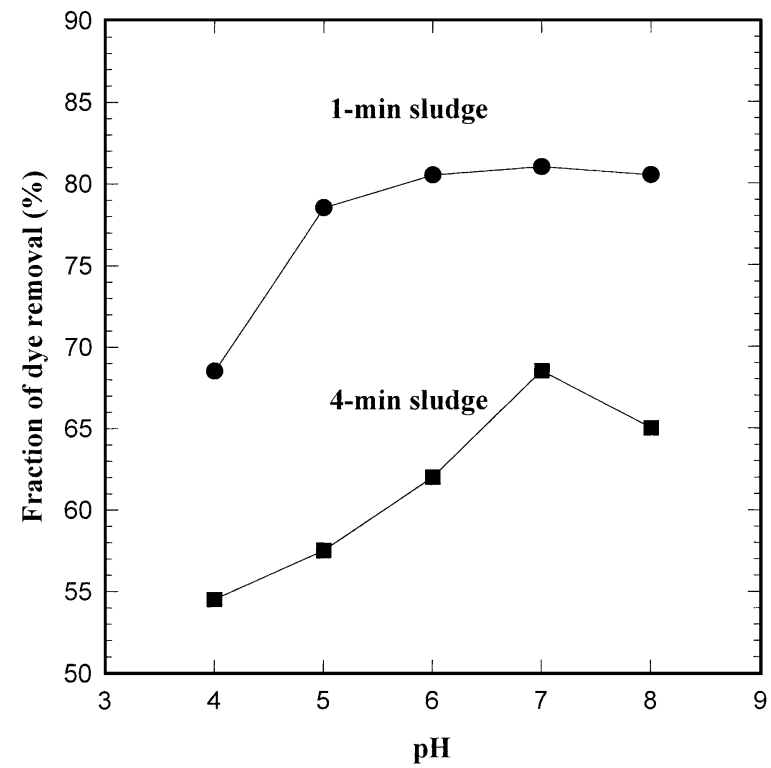

Fig. 5. Dye removal at various pH values. $30{ }^{\circ} \mathrm{C}$. are positively charged in the solution. Also, dye adsorption was seen to become increasingly efficient with increasing temperature, which is consistent with the literature (Lee et al., 1990; Mall and Upaphyay, 1995). High temperatures enhance the mobility of large dye molecules on and within the sludge matrix, and produce a swelled sludge sample interior structure that allows easy penetration of large dye molecules through the sludge matrix.

The maximum adsorption of Rhodamine $6 \mathrm{G}$ on microwave treated sludge adsorbent is an order below that for commercial activated carbon (Annadurai et al., 2001). However, the reuse of waste activated sludge is appealing in terms of resource utilization.

\subsection{Particle surface morphology}

Fig. 7 displays the SEM images of the 1-min sludge before and after adsorption. The thermally treated sludge particles (Fig. 7a) have a porous structure, relating to the potential to adsorb foreign ions from an aquatic environment. However, following dye adsorption, the particle surface becomes much smoother than that of

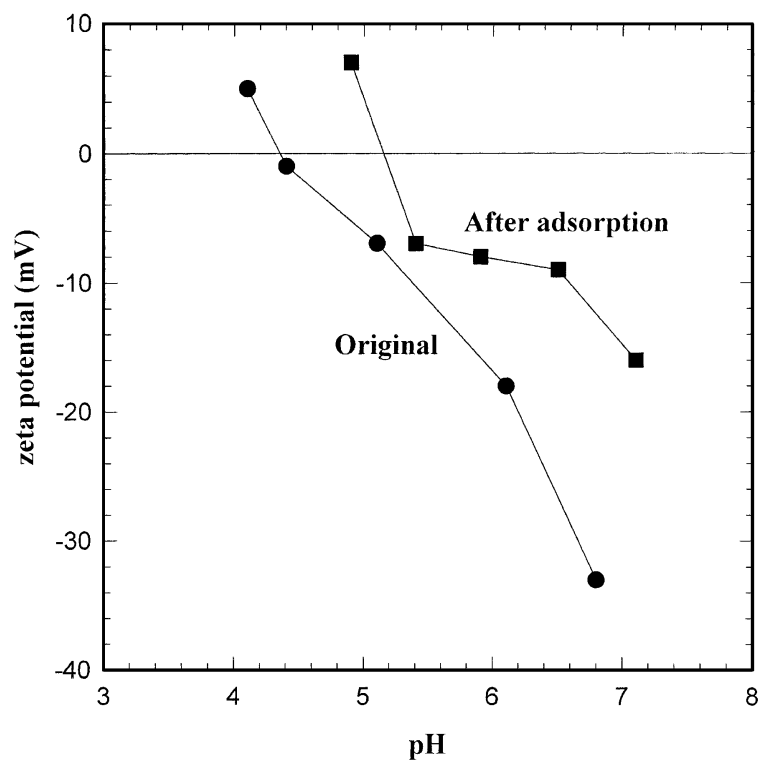

Fig. 6. Zeta potentials for 1-min sludge. $30{ }^{\circ} \mathrm{C}$. 

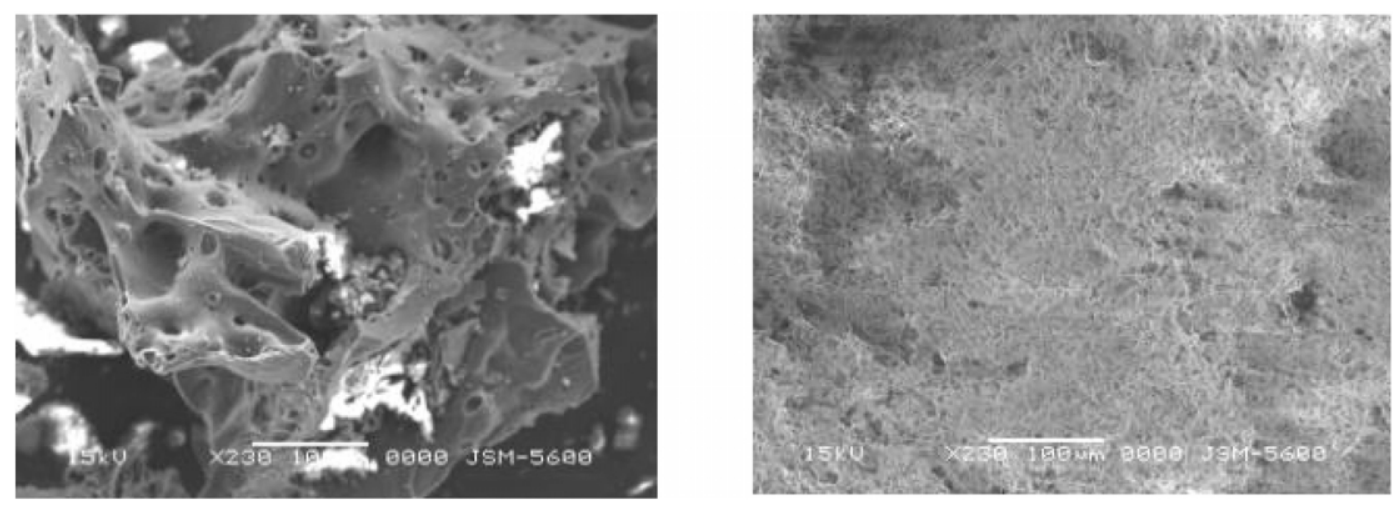

Fig. 7. (a) SEM image for 1-min sludge (before adsorption), and (b) SEM image for 1-min sludge (after adsorption).

the original particles. Restated, the porous structure deteriorates following dye adsorption.

Fig. 8 presents the SEM images of the 4-min sludge before and after adsorption. Notably, the thermally treated sludge particles (Fig. 8a) still exhibit a porous structure, but their surface roughness is not as significant as that of the 1-min sludge, due to the possible surface melt down during over-cooking in the 4-min sludge. Restated, over-cooking yields a less porous particle that can adsorb fewer ions, as shown in Figs. 7 and 8.

\subsection{Energy cost}

A 1-min sludge sample at $60{ }^{\circ} \mathrm{C}$ and $\mathrm{pH} 7-8$ is the most effective adsorbent for dye removal. The energy input is estimated at $(800 \mathrm{~W} \times 1 \mathrm{~min})=48 \mathrm{~kJ}$. The sensible and latent heat consumed for sludge samples is approximately $\left[\begin{array}{ll}6 & \mathrm{~g} \times 90 \% \times(540+80) \\ \mathrm{cal} / \mathrm{g}+6\end{array}\right.$ $\mathrm{g} \times 10 \% \times 0.5 \mathrm{cal} / \mathrm{g} \cdot \mathrm{K} \times 500 \mathrm{~K}] \times 4.2 \mathrm{~J} / \mathrm{g}=15 \mathrm{~kJ}$, that is, $31 \%$ of the total energy input. The rest of the input energy is dissipated for sludge carbonization and as heat lost to the surroundings. Restated, the energy of reaction could be estimated at approximately $55 \mathrm{MJ} / \mathrm{kg}$-ds (dried

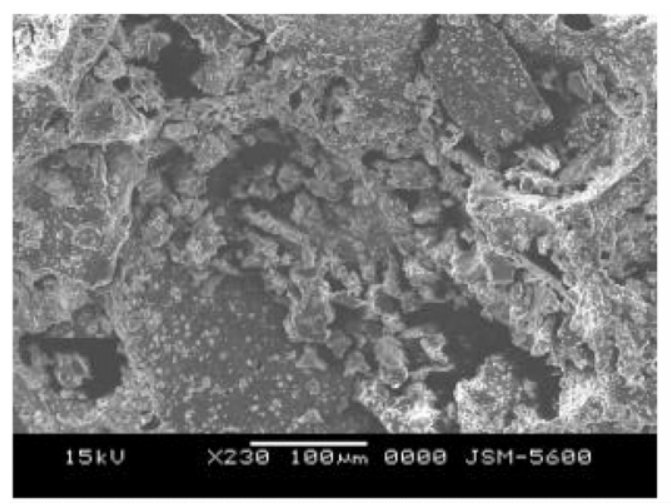

solid) while the total energy consumption is approximately $80 \mathrm{MJ} / \mathrm{kg}$-ds. Electricity accounts for most of the operational cost of microwave heating. The current cost of electricity in Taiwan is USD 4.2 cents per $\mathrm{kWh}$ (3.6 MJ). Consequently, using the present centrifugal dewatering device to yield a dewatered sludge cake of $10 \% \mathrm{w} / \mathrm{w}$ solid content, involves an energy cost of USD $0.042 \times 80 / 3.6=0.95$ (USD/kg dry solids).

However, if the sludge could be dewatered to a higher solid content, for example, $60 \% \mathrm{w} / \mathrm{w}$, the cost of the latent and sensible heat used in moisture removal could be reduced to $16.7 \mathrm{MJ} / \mathrm{kg}$ dry solids. The total cost becomes USD $0.85 / \mathrm{kg}$ dry solids, $89 \%$ of that associated with centrifuged sludge. Such an analysis reveals the importance of satisfactory sludge dewatering to the success of subsequent treatment processes.

\section{Conclusions}

This investigation examined the adsorption capacity of an adsorbent for synthetic dye, Rhodamine 6G, derived from microwave treated activated sludge. Thermal treatments at 1 and $4 \mathrm{~min}$ were conducted. Batch

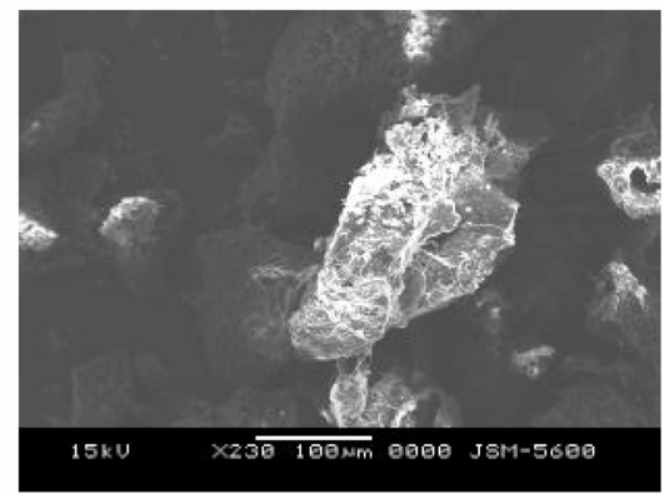

Fig. 8. (a) SEM image for 4-min sludge (before adsorption), and (b) SEM image for 4-min sludge (after adsorption). 
adsorption tests with 1- or 4-min treated samples were conducted to explore how solution $\mathrm{pH}$ and temperature affect the dye removal fraction. Favorable adsorption is achieved in a high $\mathrm{pH} /$ temperature environment. The 1-min sample adsorbed more dye on its surface at a higher rate than did the 4-min sample. The experimental findings were interpreted based on sludge sample characterization. Energy cost analysis demonstrated the feasibility of applying the proposed microwave process.

\section{Acknowledgments}

The financial support from the National Science Council, ROC, is greatly appreciated.

\section{References}

Aksu, S., Yener, J., 1998. Investigation of the biosorption of phenol and monochlorinated phenols on the dried activated sludge. Process Biochem. 33, 649-655.

Annadurai, G., Chellapandian, M., Krishnan, M.R.V., 1999. Adsorption of reactive dye on chitin. Environ. Monit. Assess. 59, 11-119.

Annadurai, G., Juang, R.Y., Lee, D.J., 2001. Adsorption of Rhodamine $6 \mathrm{G}$ from aqueous solutions on activated carbon. J. Environ. Sci. Health A, accepted.

Asfour, H.M., Fedali, O.A., Narsor, M.M., Ei-Feundi, M.S., 1985. Equilibrium studies on adsorption of basic dyes on based wood. J. Chem. Technol. Biotechnol. 35A, 21-27.

Brandt, C., Zeng, A., Deckwer, W., 1997. Adsorption and desorption of pentachlorophenol on cells of M. chlorophenolicum Pep-I. Biotechnol. Bioeng. 55, 480-489.

Bux, F., Akkinson, B., Kasan, K., 1999. Zinc biosorption by waste activated and digested sludges. Water Sci. Technol. 39 (10-11), 127-130.

Diez, M.C., Mora, W.L., Videla, S., 1999. Adsorption phenolic compounds and color from bleached karft mill effluent using allophanic compounds. Water Res. 33 (1), 125-130.

Gupta, G.S., Prasad, G., Singh, V.N., 1989. China clay as adsorbent for mordant blue-13. J. Indian Assoc. Environ. Manage. 16, 159-179.

Gurusamy, G., Elangovan, R., 1992. Evaluation of kinetic parameter of activated sludge chrome tannery-waste. Indian J. Environ. Prot 12, 474-483.

Ho, Y.S., Mckay, G., 1998. A comparison of chemisorption kinetic models applied to pollutant removal on various sorbents. Trans. Inst. Chem. Eng. 76B, 332-340.

Ho, Y.S., Mckay, G., 1999. Comparative sorption kinetic studies of dyes and aromatic compounds onto fly ash. J. Environ. Sci. Health A34, 1179-1204.

Ho, Y.S., Mckay, G., 2000. Batch sorber design using equilibrium and contact time data for the removal of lead. Water Air Soil Pollut. 124, 141-153.
Isaacs, M., Heywood, N., Blacke, N., Alderman, N., 1995. Getting a grip on sludge. Chem. Eng. 102, 80-90.

Jeyaseelan, S., Qing, L.G., 1994. Development of adsorbent/ catalyst from municipal waste waster sludge. Water Sci. Technol. 34 (3-4), 499-505.

Lee, C.K., Low, S., Chow, C.W., 1990. Chrome sludge as an adsorbent for color removal. Environ. Technol 17, 1023-1028.

Mall, I.D., Upaphyay, S.N., 1995. Removal of basic dye from wastewater boiler bottom ash. Indian J. Environ Health 37, $1-4$.

Martin, M.J., Balaguer, M.D., Rigola, M., 1999. Microwave treatment as a new option for sludge recycling. Proceedings of the IAWQ Specialised Conference on Disposal and Utilisation of Sewage Sludge: Thermal Methods and Application Modalities, Greece, pp. 593-596.

Mckay, G., Allen, S.J., McConvery, I.F., Otterburn, M.S., 1981. Transport process of coloured ions by peat particles. J. Colloid Interf. Sci 80, 329-339.

Mckay, G., Blair, S.J., Gardener, J.K., 1982. Adsoption of dye on chitin: I. equilibrium studies. J. Appl. Polym. Sci 67, 3043-3057.

Nassar, M.M., Guendi, M.S., 1991. Cooperative cost of color removal from textile effluents using natural adsorbents. J. Chem. Tech. Biotechnol. 50, 257-262.

Nawar, S.S., Doma, H., 1989. Removal of dyes from effluents using low cost agriculture by products. Sci. Total Environ. 79, 271-279.

Panswed, J., Wangchaisuwan, S., 1986. Mechanism of dyeing waste water color removal by magnesium carbonate: hydrated basic. Water Sci. Technol. 18, 139-144.

Singh, V.N., Mishra, G., Panday, K.K., 1984. Removal of congored by wollastonite. Indian J. Chem. Technol. 22, 70-71.

Sunil, K.K., Kamala, K.P., Srivastava, R.M., 1987. Removal of victoria blue from aqueous solution by fly ash. J. Chem. Technol. Biotechnol. 38, 99-104.

Ulku, Y., Goksel, N.D., Celal, F.G., 1999. Effect of chromium (VI) on the biomass yield of activated sludge. Enzyme Microbiol. Technol 25, 48-54.

Vriens, L., Nihoul, R., Verachtert, H., 1989. Activated sludges as animal feed a review. Biol. Wastes 27, 161-207.

Weber, W.J., Morriss, J.C., 1963. Kinetics of adsorption on carbon solution. J. Sanitary Eng. Div. ASCE 89, 31-59.

Wu, F.C., Tseng, R.L., Juang, R.S., 2001. Kinetic modeling of liquid-phase adsorption of reactive dyes and metal ions on chitosan. Water Res. 35, 613-618.

Yoshida, H., Akihide, O., Kataoka, T., 1993. Adsorption of acid dye cross-linked chitosan fibers-quilibria. Chem. Eng. Sci. 48, 2267-2272.

Zumriye, A., Derya, A., Elif, R., Burcin, K., 1999. Simultaneous biosorption of phenol and nickel from binary mixtures onto dried aerobic activated sludge. Process Biochem. 35, 301-308. 